\title{
Desafios da universidade pública brasileira na hipermodernidade
}

\section{Challenges of brazilian public university in the hypermodernity}

Carla Gandini Giani Martelli ${ }^{1}$

\begin{abstract}
Resumo
Este artigo parte do pressuposto de que os dilemas e desafios por que passa a universidade pública brasileira são resultados de um processo mais amplo que atinge toda a sociedade: o Brasil tem que lidar com problemas específicos derivados de seu processo de modernização, ao mesmo tempo em que está pressionado pelos novos desafios que advém do processo de globalização hipermoderna. Num diálogo com a bibliografia especializada, o artigo tem como objetivo mostrar como essa imbricação moderno/hipermoderno coloca a universidade pública brasileira diante de demandas cada vez mais complexas e diversificadas.
\end{abstract}

Palavras-chave: Universidade pública. Globalização. Hipermodernidade. Processo de Bolonha.

\section{Abstract}

This article supposes that the Brazilian public university has dilemmas and challenges due to a more complex process that affects the whole society: Brazil has to deal with specific problems of its modernization process, at the same time that it is under pressure by the new challenges that are resulted from the globalization process. Based on a specialized literature, the aim of this article is to show how this interweaving modern/hypermodern process is challenging Brazilian public university toward more and more complex and diversified demands.

Key words: Public University. Globalization. Hypermodernity. Bologna process.

\section{A novidade da globalização hipermoderna}

Não há como negar a importância que o tema da globalização assume para a compreensão da época moderna atual. Das exaustivas discussões a respeito do tema, conclui-se que não há consenso sobre o caráter de novidade da globalização atual. Muitos autores afirmam que a globalização sempre existiu, sobretudo, desde os primórdios do capitalismo, como um sistema mundial e mundializador. As grandes navegações dos séculos XV e XVI aparecem como marco importante da globalização, pensada a partir da crescente integração econômica, política e cultural

\footnotetext{
${ }_{1}^{1}$ Professora Doutora do Departamento de Antropologia, Política e Filosofia da Universidade Estadual Paulista Júlio de Mesquita Filho, UNESP. E-mail: cmartelli@fclar.unesp.br.
}

Esta obra foi licenciada com uma Licença Creative Commons - Atribuição 3.0 Não Adaptada. 
das nações. E desde então, muitas denominações apareceram para marcar as várias fases do capitalismo. ${ }^{2}$

Para além desse debate sobre a originalidade ou não do termo globalização, o que interessa evidenciar é a percepção de que "cada época é singularmente mundial" e que "se é verdade que sempre tivemos globalização capitalista, também é verdade que nunca tivemos uma globalização como a atual" (NOGUEIRA, 2005, p. 22-23).

Parte-se, portanto, da perspectiva de que estamos vivendo uma nova etapa da modernização, na qual características anunciadas na primeira modernidade - da era industrial - são radicalizadas. A sociedade globalizada atual radicalizou e intensificou vários aspectos anunciados na modernidade e, paradoxalmente, impingiu-lhe novas características. Estamos, portanto, vivendo a segunda modernidade - da era do conhecimento. Partindo de diferentes abordagens, vários autores conferem à sociedade atual um caráter de "novidade". Reconhecem que os componentes típicos do projeto moderno permanecem ativos, mas se aprofundam e se ampliam, ou seja, o projeto moderno não se esgotou, mas foi reorganizado sob uma nova cultura material. Giddens (1991) fala em "Modernidade Tardia", Beck (1997), em "Modernidade Reflexiva" ou em "Segunda Modernidade", Lipovetsky (2004) fala em "Hipermodernidade", Bauman (2001) fala em "Modernidade Líquida", para citar alguns exemplos.

A novidade dessa fase do capitalismo se deu graças ao desenvolvimento das tecnologias da informação, as quais permitiram, como em nenhum outro momento da história, derrubar fronteiras espaço-temporais por meio de conexões planetárias, em tempo real. Para muitos autores, portanto, a inovação da tecnologia da informação é o ponto central para explicação das transformações que ocorreram no mundo, pois que, ao transformar nossa cultura material, penetra todas as esferas da atividade humana. Seria um processo historicamente novo, porque somente nas últimas décadas do século $X X$ se constituiu um sistema tecnológico telecomunicações, sistemas de informação interativos e transporte de alta velocidade em âmbito mundial, para pessoas e mercadorias - que tornou possível a

\footnotetext{
2 Singer fala em globalização negativa ou desglobalização de 1930-45, globalização dirigida ou keynesiana, de 1945-73, globalização neoliberal, de 1973, em diante. Cf. SINGER, P. Desafios com que se defrontam as grandes cidades brasileiras. IN: SOARES, J.A; CACCIA-BAVA, S. Os desafios da Gestão Municipal Democrática. São Paulo: Cortez, 2002.
}

Cad. de Pesq. Interdisc. em Ci-s. Hum-s., Florianópolis, v.14, n.104, p.151-177, jan/jun 2013 
globalização (CASTELLS, 1999). ${ }^{3}$

Partindo de um poderoso recurso metafórico, Bauman mostra que a revolução da tecnologia da informação e da comunicação permitiu a conversão da "modernidade sólida" em "modernidade líquida". Estaríamos, por esse viés, vivendo um processo constante de derretimento das estruturas da sociedade. "Fluidez", qualidade de líquidos e gases, seria a principal metáfora para o estágio presente da era moderna. As estruturas são fluidas, não têm formatos prontos, se moldam ao espaço. Na modernidade sólida, vivia-se num tempo-espaço com estrutura, um tempo-espaço rijo, sólido, durável.

Nesse mundo estruturado, uma pessoa podia perder-se, mas também podia
achar seu caminho e chegar exatamente aonde pretendia estar (...) a
estrutura estava em seu lugar antes de qualquer proeza humana começar, e
durava o tempo suficiente, inabalável e inalterada, para levar a cabo a
proeza (BAUMAN, 1998, p. 110-11).

$\mathrm{Na}$ modernidade líquida, no entanto, a experiência de viver é como a experiência de um jogador: "no jogo da vida dos homens e mulheres pós-modernos, as regras do jogo não param de mudar no curso da disputa". A estratégia é manter o jogo, considerando apenas o curto prazo, "cortar o presente nas duas extremidades, separar o presente da história; aplanar o fluxo do tempo num presente contínuo". Não deve haver mais "para frente" ou "para trás", o que conta é exatamente a habilidade de se mover e não ficar parado. "O nome do jogo é mobilidade", afirma Bauman (1998, p. 113-114). Mobilidade para jogar com formas que se moldam a cada partida, já que nenhuma estrutura permanece a mesma.

O "derretimento dos sólidos" é um traço característico da modernidade - O Manifesto Comunista, de Engels e Marx, já anunciara esse processo há um século e meio-, mas ele se radicalizou na sociedade atual. As novas possibilidades abertas pela revolução informacional penetraram todas as estruturas da sociedade, da política ao mundo do trabalho, das tradições à formação do eu; tudo se abala e entra em processo de derretimento, com velocidade e dinamismo ímpares. E então, tudo precisa ser construído de novo, para ser novamente posto em xeque num processo interminável, frenético e constante.

A reflexividade é outro traço da modernidade líquida: estamos todos expostos

\footnotetext{
${ }^{3}$ Sobre a importância da tecnologia da informação nas transformações estruturais do mundo do final do século XX, ver também lanni (1999); Giddens (2002); Harvey (2003).

Cad. de Pesq. Interdisc. em Ci-s. Hum-s., Florianópolis, v.14, n.104, p.151-177, jan/jun 2013
} 
a um processo intenso de informação e de possibilidades que nos leva à reflexão e a escolhas constantes. Para tudo o que se faz, instituições e indivíduos são expostos a uma variedade de opções. As escolhas não estão dadas de antemão. Giddens (1991) observa que vivemos hoje em uma ordem "pós-tradicional", na qual as certezas da tradição e do hábito são substituídas pela dúvida radical. A vida moderna e capitalista dialoga e contrasta somente consigo própria, tornando-se reflexiva, como diz Beck (1997). As referências dadas pela tradição são postas em xeque; a ordem calculada, previsível, assegurada pela ciência e pela tecnologia, muda de cara. Nada parece seguro. A incerteza e a desconfiança governam nossa época. Todos os aspectos da vida - das práticas sociais às instituições, do associativismo às formas do eu - precisam ser construídos reflexivamente. A "segunda modernidade" se revê a si própria e se autodestrói o tempo todo, para com isso seguir adiante e se recriar. A necessidade de construção reflexiva implica um processo de questionamento, de dúvida e de escolhas permanentes. Como mais nada tem uma estrutura sólida e permanente, tudo está posto num processo de construção e desconstrução constante. $E$ as escolhas têm implicações globais e imprevisíveis.

Os efeitos do processo de globalização podem ser observados no mundo do trabalho. Modificam-se técnicas produtivas, formas de organização dos processos produtivos, condições técnicas, jurídico-políticas e sociais, de produção e reprodução das mercadorias, materiais e culturais, reais e imaginárias. A nova divisão transnacional do trabalho envolve a redistribuição das empresas, corporações e conglomerados por todo o mundo. Em lugar da concentração da indústria, centros financeiros, organizações de comércio, agências de publicidade e mídia impressa e eletrônica nos países dominantes, verifica-se a redistribuição dessas e outras atividades por diferentes países e continentes. Forma-se toda uma cadeia mundial de cidades globais que passam a exercer papéis cruciais na generalização das forças produtivas e relações de produção em moldes capitalistas, bem como nas estruturas globais de poder. Simultaneamente, ocorre a reestruturação de empresas, em conformidade com as exigências da produtividade, agilidade e capacidade de inovação, abertas pela ampliação dos mercados, em âmbito nacional, regional e mundial. O fordismo, como padrão de organização do trabalho e produção, passa a combinar-se com a flexibilização dos processos de trabalho e produção ou ser substituído por ela, num padrão mais sensível às novas 
exigências do mercado mundial, que combina produtividade, capacidade de inovação e competitividade, conforme assinala Harvey (2003).

Para os trabalhadores, os novos métodos de trabalho implicaram tanto uma intensificação dos processos de trabalho quanto uma aceleração na desqualificação e requalificação, necessárias ao atendimento de novas exigências no mundo do trabalho. $\mathrm{O}$ acesso ao conhecimento científico e técnico sempre teve importância na luta competitiva. $\mathrm{Na}$ era da acumulação flexível, num mundo de rápidas mudanças de gostos e necessidades, o conhecimento da última técnica, do mais novo produto, da mais recente descoberta científica, implica a possibilidade de alcançar uma importante vantagem competitiva. O próprio saber se torna uma mercadoria-chave, a ser produzida e vendida a quem puder pagar mais, sob condições que são elas mesmas cada vez mais organizadas em bases competitivas. O controle do fluxo de informações e dos veículos de propagação do gosto e da cultura populares também se converteu em arma vital na batalha competitiva (HARVEY, 2003).

O novo, o fugidio, o efêmero, o fugaz e o contingente da vida moderna são acentuados, em vez dos valores mais sólidos implantados na vigência do fordismo. O novo padrão técnico-econômico impõe crescente intensidade e complexidade dos conhecimentos desenvolvidos e acelerada incorporação de conhecimentos nos bens e serviços produzidos e comercializados. Informação e conhecimento são transformados em força produtiva determinante. Trata-se, portanto, de um novo padrão de acumulação capitalista. Uma das características desse novo padrão é a tendência à "desmaterialização", ou seja, a tendência à diminuição absoluta e relativa da importância da parte material usada na produção de bens e serviços. Os softwares, por exemplo, podem ser desenvolvidos, produzidos, adquiridos, distribuídos, consumidos e descartados sem necessariamente envolver a criação de novas formas materiais. As mudanças introduzidas pelo novo padrão de acumulação têm caráter bastante amplo, pois que são adotadas novas práticas de produção, comercialização e consumo de bens e serviços, bem como novos saberes e competências e novos aparatos e instrumentais científicos e produtivos (LASTRES et al., 2002, p. 61).

A percepção de que os ciclos de vida dos produtos e processos são cada vez menores tem levado alguns autores a falar em "economia da inovação perpétua". Tanto gerar como absorver inovações passa a ser o objetivo principal no jogo competitivo atual. Mas, para tanto, é preciso acesso aos conhecimentos necessários 
para incrementar o processo de inovação. Em tempos de hipermodernidade, dinamismo e complexidade são palavras de ordem. Também para o conhecimento. E esse caráter complexo e dinâmico dos novos conhecimentos "requer ênfase especial no aprendizado permanente e interativo, como forma de indivíduos, empresas e demais instituições tornarem-se aptos a enfrentar novos desafios e capacitarem-se para uma inserção mais positiva no novo cenário" (LASTRES et al., 2002, p. 61).

Diante desse novo cenário, a missão da universidade pública vem sendo objeto de discussão, tanto por parte daqueles que estão imediatamente mais ligados ao setor produtivo, como daqueles que estão mais ligados ao setor acadêmico. A ideia consensual é a de que na sociedade atual, com a inovação constante das formas de produção da vida, a universidade se vê pressionada a responder às expectativas, às tarefas e às funções crescentemente alargadas e complexas, ampliadas pela forte demanda por escolarização superior. Na perspectiva de Jack Peltason, na sociedade pós-industrial, na qual o que você sabe é mais importante do que o que você possui, as universidades e faculdades se tornarão cada vez mais essenciais.

Não seria tão grande exagero dizer que as universidades e faculdades
estão se tornando as instituições centrais para o bem-estar nacional e estão
sendo o que a igreja foi no passado - os preservadores das tradições, os
produtores de riqueza, fonte de conhecimento, o campo para o
desenvolvimento da tecnologia e patrocinadores das artes (PELTASON
apud SINGER, 2001, p. 305).

Seja como for, parece não ser exagero afirmar que não estamos diante de uma simples fase de mundialização do capital, mas, sim, estamos diante de um fenômeno mais profundo,

capaz de convulcionar (sic) e de alterar aquilo que constituía os eixos constitutivos da mentalidade coletiva e do agir social: a globalização mostrase como uma verdadeira 'revolução temporal-espacial-social', que modifica e influencia de modo expressivo a vida cotidiana como um todo (NOGUEIRA, 2006).

A universidade não está fora desse processo. Ao contrário, ela reflete os conflitos e as tensões por que passa a sociedade. E é disso que se falará neste artigo. 


\section{Um começo tardio}

Assim, como o estabelecimento de um sistema público de educação básica foi tardio no Brasil, também o caráter tardio marca o ensino superior. As primeiras universidades datam da década de 1930, período de grande modernização do país, que enfrentou uma verdadeira revolução cultural e profundas reformas em todos os níveis de ensino; a bandeira era ensino primário público, universal e gratuito. ${ }^{4}$

O período de 1945-1965 se destaca por um crescimento acelerado do ensino superior: registra-se um salto de 21 mil para 182 mil estudantes matriculados no período. O governo militar, na contramão das reivindicações anteriores, favoreceu enormemente a iniciativa privada no campo educacional. $E$ isto porque, como mostra Cunha (2007), desde os anos do 'milagre econômico', a ampliação das camadas médias propiciou uma clientela ávida por escola privada, não só como símbolo de status prestigioso, mas, também, como alternativa para o ensino público que se deteriorava a cada ano, justamente por força das políticas elaboradas e implementadas pelos empresários do ensino que ocupavam os postos diretivos dos sistemas de educação, nos níveis federal, estadual e municipal. Estava sendo posto em xeque, a partir de então, o caráter elitista do ensino superior, que nasceu no período Monárquico, com o objetivo de formar profissionais necessários ao aparelho do Estado e às demandas da elite local.

Como observa Durham (2005), também é verdade que o governo militar promove uma profunda reforma do ensino superior, instituindo um programa modelar de apoio à pós-graduação e à pesquisa universitária e introduzindo o regime de trabalho em tempo integral nas universidades federais. Foi a chamada Reforma de 1968 que instituiu a universidade considerando os três elementos do tripé - ensino, pesquisa e extensão. Sua doutrina foi elaborada com base no idealismo alemão, partindo dos princípios humboldtianos, mas o modelo organizacional proposto para o ensino superior brasileiro era norte-americano, resultando na estrutura departamental, conhecimento organizado em disciplinas, currículos contabilizados por créditos, entre outros.

A Reforma de 1968 produziu efeitos paradoxais no ensino superior brasileiro.

\footnotetext{
${ }^{4}$ A primeira universidade brasileira data do século $X X$, enquanto as primeiras europeias e norteamericanas aparecem entre os séculos XII e XIX, como as de Bolonha-1108; Oxford-1249; Cambridge-1284; Coimbra-1290; Praga-1348; Harvard-1636; Yale-1701; Berlin- 1810, para citar alguns exemplos. Cf. LIMA et al, 2000, p. 11.
}

Cad. de Pesq. Interdisc. em Ci-s. Hum-s., Florianópolis, v.14, n.104, p.151-177, jan/jun 2013 
Por um lado, modernizou uma parte significativa das universidades federais e determinadas instituições estaduais e confessionais, que aderiram às suas recomendações, criando condições propícias para que articulassem atividades de ensino e pesquisa, dentre outras coisas. Por outro, abriu condições para o surgimento de um ensino privado que reproduziu o que Florestan Fernandes denominou o "antigo padrão brasileiro de escola superior", referindo-se a instituições organizadas a partir de estabelecimentos isolados, voltados para a mera transmissão de conhecimentos de cunho marcadamente profissionalizantes e distanciados da atividade de pesquisa, que pouco contribuem com a formação de um horizonte intelectual crítico para a análise da sociedade brasileira e das transformações de nossa época (FERNANDES apud MARTINS, 2009).

Entre 1980 e 1985, ocorreu uma pequena diminuição das matrículas no setor privado, aumentando as do ensino público. A crise econômica vivenciada pelo país no período, com o grave quadro inflacionário, aumento das taxas de desemprego, pode explicar a desaceleração da expansão do ensino superior. A partir da década de 1990, intensificou-se a presença das instituições particulares no interior do campo do ensino superior. Várias razões são apontadas por analistas: a criação do Conselho Nacional de Educação (no lugar do extinto CFE), que conferia ao MEC uma maior autonomia na condução do processo de expansão do ensino superior e, fundamentalmente, a incorporação de determinados princípios das agendas de organismos internacionais, que recomendavam a desregulação do ensino superior, a retração de gastos governamentais para o ensino superior com incremento de investimentos na educação básica.

Daí para frente, o ensino privado experimenta, não só no Brasil, mas em vários países do mundo, o comando da expansão do ensino superior.

\section{Modelo humboldtiano X processo de Bolonha}

A história das políticas públicas no Brasil mostra que as reformas que ocupam as agendas governamentais são bastante influenciadas pelo fundamento da política externa, ou seja, por modelos estrangeiros, relatórios teóricos e demandas transnacionais. A reforma universitária de 1968, por exemplo, sofreu a influência do modelo departamental da universidade norte-americana. Nos anos 1990, as reformas do Estado e da educação superior tiveram por referencial teórico o

Cad. de Pesq. Interdisc. em Ci-s. Hum-s., Florianópolis, v.14, n.104, p.151-177, jan/jun 2013 
liberalismo ortodoxo do Banco Mundial. Já no início do século XXI, qualquer movimento de reforma universitária que se pretende implantar no mundo, entre outras inspirações e referenciais, obriga-se a fazer menção ao Processo de Bolonha (LIMA et al., 2008).

O Processo de Bolonha é o resultado de processos políticos e de reformas institucionais realizadas por cada governo nacional europeu ou respectivas entidades descentralizadas. Tem como objetivo principal a edificação de um "Espaço Europeu de Ensino Superior" que viabilize a internacionalização das universidades, facilite a mobilidade de alunos e docentes, promova a empregabilidade dos cidadãos europeus e concorra para o desenvolvimento econômico, social e humano da Europa, a consolidação e enriquecimento da cidadania europeia e o aumento da competitividade com outros sistemas de ensino do mundo (EUA e Japão, em especial). Mas muitos chamam a atenção para outro aspecto: denunciam a existência de "uma agenda oculta de Bolonha", que seria orientada não por questões educacionais, mas pelas questões da economia, procurando resolver o problema da elevação dos salários europeus que, no quadro da economia global, afetam os índices de competitividade da Europa. Daí a crítica: tal dinâmica economicista na educação, ao priorizar eficiência e competitividade, deixa em segundo plano os preceitos democráticos que deveriam nortear os processos de produção e formação no ensino superior público (MORGADO, 2009, p. 50-51).

Além do fato de negligenciar os preceitos democráticos, as críticas se dão no sentido de mostrar que em seus preceitos não são levadas em consideração as particularidades, o contexto, a situação de partida de cada instituição de ensino superior, impondo suas regras para homogeneizar todas as instituições.

Mas, em sua defesa, muitos dizem que o Processo de Bolonha é expressão dessa época, pois a revolução da informação e da comunicação - e todo o processo de globalização que dela decorre -, implica pensar a universidade para além de seus muros. Como afirma Marcovitch (2002, p. 8), "a missão acadêmica é algo que se reconceitua a cada época e jamais será definida com exatidão ao longo da história". Assim, nas últimas décadas, a universidade passou a ser uma instituição transnacional, sendo impossível examiná-la somente à luz do seu entorno imediato. Por essa razão, prossegue o autor, 
outro país, teremos de contemplar o mundo em sua totalidade. São as transformações mundiais, em todas as áreas da atividade humana, que devem mover as estratégias acadêmicas. $E$, nesse cenário, as bem-vindas inovações da tecnologia de informação têm um papel irreversível (MARCOVITCH, 2002, p. 8),

Ou seja, num mundo que se globaliza com a força e a velocidade das tecnologias da informação e da comunicação não dá para negar as novas demandas transnacionais que se colocam para a universidade.

Mas, também, como observam outros, não é possível deixar de apontar as implicações da subserviência do Estado nacional para com uma agenda transnacional. Ou seja, os estados nacionais encontram-se pressionados por duas forças: por um lado, os movimentos globais e os projetos supranacionais e, por outro, os contextos nacionais concretos, com características e configurações históricas sociais e culturais muito próprias. O Processo de Bolonha é exemplar dessa tendência a um "conhecimento escolar internacional", no qual haveria uma progressiva europeização do currículo, enfraquecendo as territorialidades curriculares nacionais, regionais e locais (MORGADO, 2009, p. 49). Também se aponta a perda de protagonismo dos estados nacionais, a tal ponto que alguns autores chegam a falar que está em marcha um processo de "desnacionalização" da educação superior em favor da "europeização" do ensino superior, numa clara opção por políticas de liberalização e pela "necessária harmonização para a emulação e a competitividade, vencendo barreiras e fronteiras tradicionais" (LIMA et al., 2008, p. 12).

Nos primórdios da universidade moderna, Humboldt imaginou uma academia independente e autônoma, dedicada à busca da verdade e do conhecimento, que daria frutos para o Estado e para o bem-estar dos cidadãos. Para tanto, era conferido aos professores liberdade de ensinar e de investigar sem estarem sujeitos a qualquer programa predefinido; a universidade era vista como um espaço de "discussão livre e independente das questões criticas da sociedade", sendo ao mesmo tempo encarada como parceira do Estado a quem incumbia cooperar na construção da identidade política da nação e na "preservação e desenvolvimento da cultura nacional". Caberia ao Estado, portanto, criar condições para a subsistência e o bom funcionamento da universidade, bem como a regulação do sistema de ensino, com direito a interferir no que considerava conhecimento útil e nas determinações sobre os currículos, planos de estudo, parâmetros de avaliação, etc. (MORGADO, 
2009, p. 46).

Universidade ao lado do Estado, num projeto de construção da identidade política da nação e na preservação e desenvolvimento da cultura nacional. O respeito ao solo brasileiro, aos seus problemas reais, às peculiaridades e ao modo de pensar do país deveriam ser, então, o ponto de partida de qualquer e toda política educacional. A construção de um saber livre e desinteressado era o objetivo que movia a universidade. Mas o momento atual sinaliza para outra direção.

\section{A radicalização do saber interessado}

A missão da universidade pública no mundo de hoje vem sendo objeto de discussão, tanto por parte daqueles que estão imediatamente mais ligados ao setor produtivo, como daqueles que estão mais ligados ao setor acadêmico. A ideia consensual é a de que na sociedade atual, com a inovação constante das formas de produção da vida, a universidade se vê pressionada a responder às expectativas, tarefas e funções crescentemente alargadas e complexas, ampliadas pela forte demanda por escolarização superior.

Foi na década de 1980 que a reflexão sobre a teoria e a prática nas universidades se intensificou, tendo como pano de fundo as mudanças na estrutura econômica dos países, provocadas pela emergência e rápida disseminação das novas tecnologias de informação e comunicação. A reestruturação da economia já se mostrava mais dependente do conhecimento do que os sistemas de produção do século passado e isto porque a acelerada expansão de formas novas de produção e reprodução da vida material passa a alterar rapidamente o tecido econômico e social dos países, que tinham seu processo produtivo assentado na era industrial. A exigência por novos profissionais preparados para compor a nova estrutura pósindustrial incidiu diretamente sobre os cursos acadêmicos de formação de profissionais, questionando as tradicionais estruturas de organização acadêmica e de produção do conhecimento. O surgimento do Vale do Silício, berço das modernas tecnologias da informação e comunicação, é ilustrativo da explosão de conhecimento que vinha das empresas, demandando profissionais preparados para atender às suas novas necessidades. É desse processo que se intensifica a necessidade de entrelaçamento entre a indústria nascente e a universidade, a ponto de ser cada vez mais criticada a distinção entre ciência básica e aplicada. Assim

Cad. de Pesq. Interdisc. em Ci-s. Hum-s., Florianópolis, v.14, n.104, p.151-177, jan/jun 2013 
também, a distância entre pesquisa e empreendimento torna-se cada vez menor (ARBIX; CONSONI, 2011).

É por isso que alguns autores falam que a universidade, em vários países do mundo, estaria vivendo uma "segunda revolução acadêmica", no sentido em que ensino e pesquisa passam a ter uma forte atuação de transferência de conhecimento para a sociedade. Como observa Etzkowitz, a universidade viveu uma verdadeira revolução acadêmica no século XIX, quando adicionou à docência uma segunda missão, a da pesquisa. A partir dos anos de 1970, a universidade estaria vivendo outra revolução, na medida em que tem sido pressionada a ampliar o espectro de sua contribuição para o desenvolvimento econômico e social. Disso resultou a nova missão da universidade: desenvolver pesquisas que possam contribuir para o desenvolvimento da sociedade. Chega-se mesmo a falar numa nova terminologia para a universidade: "universidade empreendedora" (ETZKOWITZ apud ARBIX; CONSONI, 2011, p. 209).

Os países asiáticos teriam atendido ao apelo "empreendedor" da universidade, tornando-se capazes de gerar e incentivar inovações que desencadeassem fortes processos de qualificação e elevação do grau de competitividade das empresas e de suas respectivas economias. Na observação de alguns pesquisadores, esse não seria o caso do Brasil, uma vez que aqui a universidade ainda permaneceria insulada, carecendo de canais de ligação capazes de viabilizar uma sintonia com os esforços que o país estaria fazendo para se desenvolver. Por essa perspectiva, seria urgente a necessidade de se ampliarem a sinergia e os fluxos de conhecimento entre universidade e sociedade, determinantes que são para a absorção, a aprendizagem e a geração de inovação e tecnologia. Nesta direção, alguns passos importantes já começam a ser dados: na virada do século, a promoção da inovação foi incorporada aos planos de desenvolvimento nacional, como o ilustram a criação dos Fundos Setoriais, em 1999, a nova Política Industrial, Tecnológica e de Comércio Exterior, assim como a Lei de Inovação de 2004 e a Lei do Bem, de 2005 (ARBIX; CONSONI, 2011, p. 209, 212).

A década de 1990 intensifica ainda mais esse debate colocando como alvo de discussão conceitos tais como parcerias, redes, sistema regional de inovação, aprendizagem, clusters industriais, etc. Todos eles refletindo a crescente interdependência entre vários atores e temas em níveis locais, regionais e globais. $\mathrm{E}$ é exatamente essa confluência de interesses que faria aumentar a necessidade de 
criação de novos tipos de interação entre setor público, comércio e várias instituições acadêmicas, objetivando a criação e a aplicação de novos conhecimentos (MELLO, 2004).

Alguns autores têm se destacado no debate acerca de novas formas de produzir e aplicar conhecimento. Gibbons (1994), por exemplo, fala da necessidade de se desenvolverem pesquisas com a finalidade de resolver problemas práticos e atender demandas econômicas ou sociais. O novo modo de produção do conhecimento - chamado "Modo 2" -, deve ser mais transdisciplinar do que disciplinar e deve partir de uma heterogeneidade institucional, ou seja, deve ser organizado e desenvolvido sob formas de associações heterogêneas, não hierárquicas. Os grupos de pesquisa, por exemplo, devem ser menos institucionalizados, permitindo que as pessoas participem deles só o tempo necessário para a resolução do problema em pauta, podendo ser dissolvidos para a formação de novos grupos de pesquisa, os quais, por sua vez, estarão temporariamente formados até a resolução dos novos objetivos. É por essa razão que se fala em maior flexibilização, pois que a rigidez das estruturas anteriores não atenderia às novas exigências de responder às questões práticas apresentadas pela realidade.

Nessa mesma linha, outros autores enfatizam uma maior interação entre universidade-indústria-governo, como é o caso de Leydesdorff e Etzkowitz (1998), a partir da abordagem da "Hélice Tríplice". ${ }^{5}$ Entendem que o conhecimento se desenvolve dinamicamente, fluindo tanto no interior das organizações como através das fronteiras institucionais e que a geração de riqueza pode se dar através do conhecimento produzido por arranjos institucionais entre organizadores do conhecimento, tais como universidades, indústrias e agências governamentais. A base de conhecimento e seu papel na inovação podem ser explicados em termos de mudanças nas relações entre universidade, indústria e governo. Ou seja, a tese da hélice tríplice é a de que a interação universidade-indústria-governo é a chave para melhorar as condições para inovação numa sociedade baseada no conhecimento, uma vez que provê uma moldura para analisar as condições e pré-requisitos

\footnotetext{
${ }^{5}$ Ver artigo no caderno Opinião, A3, da Folha de São Paulo, de 29/05/11, "Educação como fator de desenvolvimento", que fala da aplicação do modelo da Hélice Tríplice na Suécia. Segundo Annika Markovic, embaixadora da Suécia no Brasil, tal modelo "tem contribuído para o desenvolvimento de um ambiente colaborativo entre diferentes âmbitos da sociedade: o governo desenvolve os parâmetros da economia, as universidades ampliam suas bases de conhecimento e as indústrias criam novos produtos, serviços ou mercados".
}

Cad. de Pesq. Interdisc. em Ci-s. Hum-s., Florianópolis, v.14, n.104, p.151-177, jan/jun 2013 
necessários para passar de uma situação de subdesenvolvimento para a de desenvolvimento, de regiões arcaicas para regiões de alta tecnologia, etc. Por essa perspectiva, espaços de conhecimento são transformados de "fontes em potencial" para "fontes de fato" de desenvolvimento econômico e social em encontros que juntam pessoas de diferentes organizações e de diferentes formações e perspectivas, para a geração de novas estratégias e ideias. Através de um processo de discussão, essas pessoas podem chegar a apontar um curso de ação que possa superar problemas no meio ambiente local de inovação (MELLO, 2004).

Numa outra perspectiva, Funtowicz e Ravetz (1993) falam em "Ciência PósNormal", enfatizando a necessidade de uma relação harmônica entre a humanidade e a natureza. Propõe interação explícita dos problemas científicos entre aspectos epistemológicos - relativos ao conhecimento -, e os aspectos axiológicos - relativos aos valores. A "Ciência Normal" só daria conta de resolver problemas de incertezas e decisões de baixa complexidade, mas não de resolver problemas de grande incerteza e alta complexidade, como os que advêm das questões ambientais, por exemplo. A economia estabeleceu-se enquanto ciência normal a partir de um paradigma modelado explicitamente sobre a física clássica, renegando questões éticas e cognoscitivas fundamentais. E como resultado disso, apontam que as técnicas quantitativas e probabilísticas de análise de riscos, ou as análises custobenefício pautadas em critérios exclusivamente monetários, incorrerão em sérios problemas éticos e encobrirão incertezas e interesses principalmente dos grupos mais vulneráveis e das dimensões não apreendidas pelo ferramental dessas técnicas. Superar tais limitações, incrementando a qualidade dos processos decisórios, seria justamente a tarefa da nova prática científica e institucional da ciência pós-normal. Daí falarem em "economia ecológica", por meio da qual a negociação em processos políticos institucionalizados seria pautada a partir de novos conceitos e práticas construídos com o objetivo de garantir maior qualidade dos processos decisórios, de forma a atenderem as exigências de uma sociedade democrática. Ou seja, a abordagem da "Ciência Pós-Normal" acredita que as investigações interdisciplinares voltadas aos estudos de problemas ambientais constituem-se importante estratégia de transição da ciência normal para uma futura ciência pós-normal, menos fragmentada e eticamente comprometida com os interesses da civilização.

Há ainda a perspectiva defendida por Callon (1990) de "organização em Cad. de Pesq. Interdisc. em Ci-s. Hum-s., Florianópolis, v.14, n.104, p.151-177, jan/jun 2013 
rede", segundo a qual, um conjunto coordenado de atores - laboratórios públicos, centros técnicos de pesquisa, empresas, usuários e universidades -, deveriam participar coletivamente no desenvolvimento e difusão de inovações. A ideia é que houvesse numerosas interações entre esses atores na organização das relações entre a pesquisa técnico-científica e o mercado. As redes seriam organizadas em torno de três polos: o polo científico, o tecnológico e o de mercado. Esse novo modo de produção do conhecimento não seria orientado apenas para os pares, mas, também, para os não produtores de conhecimento, o que demandaria maior responsabilidade social por parte de todos os atores envolvidos.

À parte as diferenças entre as várias abordagens e as críticas que a elas possam surgir, elas demonstram que as universidades e faculdades têm se tornado as instituições centrais nessa sociedade onde o conhecimento se transformou na mercadoria mais importante, peça chave para entrada das nações no jogo competitivo global.

Como conta a história, as universidades são herdeiras das instituições do mundo greco-romano. No Ocidente cristão, assumiram formas específicas. Mas pode-se dizer que foram criadas voltadas para o saber como um fim em si mesmo, $O$ saber desinteressado. A universidade tinha como missão cultivar e transmitir o saber humano acumulado. Com a revolução industrial e a consolidação do modo de produção capitalista, surgiram exigências de especializações e técnicas que se ajustassem à nova divisão social do trabalho (WANDERLEY, 2003). Com a revolução da informação, a sociedade vive a radicalização dessas novas exigências de especialização e de técnica: o capitalismo flexível, acompanhado da nova divisão transnacional do trabalho, impõe velocidade à formação e à especialização, sob pena de deixar de fora do jogo os que não acompanham o extremo dinamismo da nova fase. Há, portanto, um aprofundamento e estreitamento das relações entre universidade e mercado que afeta a finalidade mesma da universidade. Soma-se a tudo isto a reconfiguração do papel do Estado naquilo que diz respeito às políticas sociais, incluindo as universidades públicas, como se verá a seguir. 


\section{O Estado provedor na berlinda}

Segundo Maria Helena Castro (2005), a lógica do mercado tornou-se um componente inevitável da atual configuração do ensino superior, em todo o mundo, inclusive nos sistemas mais consolidados e de tradição pública da Europa Ocidental. A antiga moldura institucional, a qual contava com o financiamento público e o controle direto pelo Estado, não resistiu às pressões impostas pelas necessidades de expansão e diversificação do setor das últimas décadas. Mesmo em países ricos como Inglaterra, Holanda e os da Escandinávia, o financiamento da expansão tem se tornado caro demais para os cofres públicos, desde os anos 1980. Nenhum governo conseguiu financiar integralmente a transição do ensino superior de um sistema de elite para um sistema de massa, assim como os governos também não conseguem mais acompanhar e avaliar, sozinhos, tudo o que passa em um setor cada vez mais dinâmico, diversificado e internacionalizado.

Tomando o caso europeu, que conta com 85\% das matrículas em instituições públicas, especialistas mostram que vários países da Europa Ocidental passaram de um modelo controlado e regulado pelo Estado para um modelo de auto-regulação, que tem as seguintes características: Estado menos intervencionista, ambiente semelhante ao mercado e níveis mais altos de responsabilidade e participação por parte da comunidade do ensino superior nos dilemas da regulação do setor. As normas que regulavam a organização do ensino foram substituídas por fórmulas de verificação de desempenho, que resultaram na montagem de novos sistemas de avaliação. As instituições foram liberadas dos controles burocráticos e incitadas a crescer e a encontrar seus próprios caminhos para responder aos novos desafios. Trata-se de uma nova engenharia político-institucional, na qual as comunidades acadêmicas e científicas começaram a compartilhar algumas funções com o governo, inclusive a de obter recursos adicionais para suplementar os subsídios que continuaram a receber dos governos, dentro de uma lógica de eficiência gerencial e financeira (CASTRO, 2005).

O caso brasileiro é bastante diferente, a começar pelo percentual de matrícula no ensino superior privado que é de $70 \%$. Numa perspectiva histórica, enquanto os países do centro do capitalismo se deparavam com os dilemas provocados pela globalização neoliberal dos anos 1980, e, então, com a crise de um modelo de Estado de Bem-Estar Social, com questões de ajuste fiscal, de reforma da

Cad. de Pesq. Interdisc. em Ci-s. Hum-s., Florianópolis, v.14, n.104, p.151-177, jan/jun 2013 
administração pública, etc., o Brasil vivia dois momentos distintos e confluentes que o colocam frente a dilemas e entraves ainda mais complexos e desafiadores. Por um lado, vivia o processo de redemocratização, de reconstrução da legitimidade e de credibilidade do Estado e de suas instituições, de enriquecimento da cidadania que, pela via dos direitos sociais, significou a busca pela universalização do sistema de proteção, como bem expressa a Carta Constitucional de 1988. Por outro lado, vivia os impasses do desmonte de um modelo de Estado e de proteção, o que significava responder ao ajuste financeiro e fiscal e aos consequentes cortes de "gastos" nas políticas sociais. Ou seja, sem ter consolidado um Estado de Bem-Estar Social como os da Europa, teve de lidar com as implicações de seu desmonte. O Ensino Superior Público, já bastante reduzido, é convulsionado por essa onda de desmontes. O Ensino Superior Privado hegemônico acaba por se beneficiar do momento, mas, apenas com raras exceções, não no que diz respeito à qualidade do ensino.

E a questão da não qualidade do ensino, desde a educação básica, coloca em risco a democratização do conhecimento, corroborando a estrutura de desigualdade e estratificação que tem assolado o país há décadas. Democratizar o acesso não é o mesmo que democratizar o conhecimento. $O$ processo de democratização do acesso, que vem ganhando corpo no Brasil, tem a ver com o processo de massificação que tende a manter a lógica da estratificação do sistema educacional. Democratizar o conhecimento implica permitir a todos participarem do processo com igualdade de oportunidades. Diz respeito

à criação das condições institucionais e comportamentais (didáticopedagógicas) necessárias para uma formação de massas igualitária ou baseada numa igualação categórica das oportunidades, de modo a propiciar a todos (e não apenas aos mais capacitados) as mesmas condições de progressão intelectual, acesso a conhecimentos e interação acadêmica (NOGUEIRA, 2005, p. 57) [grifo do autor].

Embora no final dos anos 90 haja registros de enorme crescimento da matrícula no ensino superior em todo o Brasil, estudos recentes mostram que o Brasil está longe do percentual alcançado por países desenvolvidos e em desenvolvimento naquilo que se refere à população que conclui o ensino superior. ${ }^{6}$

\footnotetext{
${ }^{6}$ Durham (2009) mostra que, enquanto o Canadá, o Japão, a Coréia do Sul, a Noruega, a Irlanda e a Bélgica têm percentuais acima de $40 \%$ da população que concluiu o Ensino Superior, o percentual brasileiro é de $10 \%$. Há uma lista de países que se colocam entre $35 \%$ e $40 \%$ e ainda outros que estão entre $20 \%$ e $35 \%$.
}

Cad. de Pesq. Interdisc. em Ci-s. Hum-s., Florianópolis, v.14, n.104, p.151-177, jan/jun 2013 
Atender à demanda por quantidade, priorizando a qualidade, tem sido o grande desafio da educação superior. Alguns autores enxergam os sistemas de avaliação que se instalaram na educação nos anos 90 como expressão dessa preocupação. Apesar de algumas inovações, especialistas observam que há omissões importantes na política educacional recente com relação, por exemplo, à crescente demanda por educação pós-secundária por parte de uma população cuja formação prévia é insuficiente para obter sucesso em instituições voltadas para a pós-graduação e para a pesquisa. Não há uma política que promova a diversificação dos tipos de estabelecimentos nem dos programas de ensino, de forma a atender às necessidades de uma demanda que se faz cada vez mais heterogênea em termos de interesses, vocações e competências. Nem todos os alunos egressos do ensino médio se interessam ou estão preparados pelo tipo de formação que é próprio das universidades - pesada carga teórica e desenvolvimento do pensamento abstrato que opere com conceitos (DURHAM, 2009).

Não só a graduação, mas, também, a pós-graduação está em descompasso com as demandas atuais, pois supõe um período muito longo de formação, quando comparado com outros países. Além do tempo de formação, há que se levar em conta o perfil do mestrado no Brasil, já que boa parte dos mestres não segue carreira acadêmica e está empregada fora da academia. A evolução das exigências do mercado de trabalho emprestou ao mestrado um valor profissional extraacadêmico que ele originalmente não possuía. O aumento de demanda foi atendido fortemente pelo sistema privado que tem crescido na oferta de ensino de pósgraduação (BALBACHEVSKY, 2005).

O processo de estratificação das universidades públicas brasileiras tende a se intensificar, na medida em que o apoio da Capes e demais agências de fomento aos bons programas de pós-graduação cria ambientes favoráveis que atraem os melhores pesquisadores e professores; a presença de massa crítica de pesquisadores permite que essas instituições consigam mobilizar mais recursos financeiros para apoiar a atividade de pesquisa, são essas as instituições responsáveis pela grande maioria dos programas de doutorado no país. Como as notas mais altas são dadas aos programas que oferecem mestrado e doutorado, tais instituições conseguem os melhores indicadores. Essa estratificação também tem um componente regional: os melhores resultados estão no Sudeste e os piores no Norte (BALBACHEVSKY, 2005).

Cad. de Pesq. Interdisc. em Ci-s. Hum-s., Florianópolis, v.14, n.104, p.151-177, jan/jun 2013 
Reverter o quadro de estratificações e desigualdades no ensino superior coloca-se como um grande desafio para autoridades e especialistas. Para além das turbulências globais que se abatem sobre o sistema de ensino brasileiro, há questões que nos são particulares, específicas, que imprimem um caráter ainda mais dramático à universidade brasileira. Por exemplo, no que diz respeito ao desenvolvimento elitista e tardio da educação superior e da precocidade do processo de privatização do setor.

E daí a confluência de demandas: o Brasil tem velhas e novas questões a resolver. Pensando a educação superior, as velhas dizem respeito, em primeiro lugar, a estrutura de desigualdade econômica e social que construímos ao longo de nossa história. Essa estrutura deságua na educação produzindo mais desigualdade e estratificação. As novas: aumento da exclusão social no mercado globalizado cada vez mais exigente e competitivo e, como consequência, intensificação da pressão por educação continuada. Também é nova a transnacionalização da universidade que permite maior mobilidade entre alunos de diversos países. Disso tudo resulta um aumento exponencial da demanda na graduação e na pós-graduação, e, então, maior diversidade e heterogeneidade da demanda atual. Também é nova a questão da reforma do Estado imposta pelas novas exigências de ajuste fiscal e de eficiência administrativa. Resulta de tudo isso um quadro de crise que pede respostas urgentes.

\section{Dilemas e contradições da universidade pública brasileira}

As crises e contradições vividas na universidade podem ser expressão deste impasse: o conhecimento virou mercadoria sem poder sê-lo nos moldes de outras mercadorias, pois traz em si características que the são peculiares. Assim, ao mesmo tempo em que não se pode tratar conhecimento como um bem de mercado qualquer, sem considerar suas características peculiares - a importância do processo na construção do conhecimento, o tempo necessário para o amadurecimento do saber crítico e da formação plena, a importância da interlocução na construção do saber -, não se pode negligenciar as pressões da sociedade atual no que se refere ao novo padrão produtivo. Não se pode, portanto, desconsiderar o aumento de demanda por informação e conhecimento, nem tampouco desprezar as inúmeras possibilidades oferecidas pelas novas tecnologias, as quais, por sua vez,

Cad. de Pesq. Interdisc. em Ci-s. Hum-s., Florianópolis, v.14, n.104, p.151-177, jan/jun 2013 
abrem algumas alternativas para atender ao aumento de demanda - a educação a distância, por exemplo.

As pressões e contradições advindas do processo de globalização são muitas. É preciso enfatizar seus efeitos, num país periférico como o Brasil. Parte-se do pressuposto de que o Brasil vive a imbricação do moderno e do hipermoderno. Em diversos aspectos podemos pensar exemplos de um Brasil que ainda está em processo de modernização, que sofre as consequências da "Primeira Modernidade". E é essa a especificidade dos países periféricos. Como observa Nogueira (2007a, p. 52), os países periféricos têm uma especificidade que pode ser explicada, em boa parte,

pelo fato de que as transições modernas, imperfeitamente explicitadas, encontram-se sobredeterminadas pela transição que está levando o mundo a se globalizar e a passar de um estágio de complexidade baixa para um estágio de complexidade alta.

Pensando um contexto que não o Brasil, Beck (2003, p. 28) fala que os povos periféricos pensam a partir das categorias de ordem da Primeira Modernidade, mas agem na "zona cinzenta e nas turbulências da Segunda". Numa outra perspectiva, Draibe (1997) mostra que os países latino-americanos, com poucas exceções - o Brasil não é exceção -, arrastaram até os tempos atuais padrões inaceitáveis de desigualdade e pobreza que foram intensamente reforçados pelos novos mecanismos da globalização, os quais aumentam a desigualdade e ampliam a exclusão. Por isso, a América Latina está exposta a um duplo desafio: reduzir a exclusão passada e atenuar a força dos mecanismos que reiteram e ampliam a exclusão na atualidade.

Também Soares (2007) aponta um duplo compromisso para o Brasil: resolver questões que dizem respeito à velha cultura institucional e à velha burocracia e, ao mesmo tempo, enfrentar os desafios apontados pelas características complexas e sofisticadas da hipermodernidade.

Assim, as pressões a que todo o globo está submetido na atual fase chegam ao Brasil e se somam aos graves problemas estruturais que se estendem na história do país - a desigualdade social, por exemplo: ainda somos um dos países mais desiguais do mundo, apesar da melhoria nos índices de pobreza apresentados nas últimas décadas. A pesquisa de Souza e Lamounier (2010, p. 1), por exemplo, mostra

Cad. de Pesq. Interdisc. em Ci-s. Hum-s., Florianópolis, v.14, n.104, p.151-177, jan/jun 2013 
a extraordinária prosperidade da economia mundial nos 20 anos que antecederam a crise de 2008-2009, a qual contribuiu para reduzir a desigualdade de renda em países como China, Índia e Brasil e, assim, abriu espaço para a mobilidade social de grandes contingentes, formando o que se tem denominado "nova classe média".

Seja como for, temos de resolver as questões da desigualdade, da miséria, da fragilidade das instituições políticas, ao mesmo tempo em que temos de enfrentar os abalos provocados pela atual fase de radicalização da modernidade que afeta, com peso e forma diferentes, todas as sociedades.

Naquilo que diz respeito à educação, as turbulências derivadas da hipermodernidade capitalista chegam ao Brasil e encontram as seguintes questões: alto índice de analfabetismo e de analfabetos funcionais, ${ }^{7}$ desigualdades regionais (Região Nordeste concentra os maiores índices de analfabetos e analfabetos funcionais), baixa qualidade da educação pública básica (como mostra o IDEB), ${ }^{8}$ exclusão digital, crescente processo de privatização da educação superior, baixa qualidade do ensino superior privado, baixa qualidade das faculdades de pedagogia, e, então, péssima formação de professores da rede de educação básica e fundamental, ${ }^{9}$ para citar apenas alguns dos graves problemas da educação no Brasil. As políticas de educação têm de enfrentar, portanto, um duplo desafio: responder às novas demandas da "era do conhecimento" - considerando as várias possibilidades dadas pelas novas tecnologias para a educação - e, ao mesmo tempo, responder às "velhas demandas", ainda não atendidas. ${ }^{10}$

\footnotetext{
7 Segundo dados do IBGE de 2007, 84,5\% das crianças de 8 a 14 anos que não sabem ler frequentam a escola, ou seja, 1,1 milhão de crianças sendo que deste total, 745,9 mil vivem no Nordeste. Cf. Folha de São Paulo, C1, 25/09/08.

${ }^{8}$ Ainda que o IDEB tenha registrado melhora nos resultados da $4^{a}$ série a partir de 2003 , tendo atingido a $8^{a}$ série em 2005, o Brasil segue muito defasado nas habilidades básicas. Por exemplo, naquilo que se refere à capacidade de leitura e compreensão de texto, $50 \%$ dos jovens de 15 anos ainda não são capazes, entre outras coisas, de localizar informações implícitas em um texto (conforme resultados da avaliação internacional PISA). Segundo a OCDE, eles terão dificuldades de participar de maneira ativa e produtiva da vida social. Mais grave ainda se torna o problema quando se leva em conta que $19 \%$ dos brasileiros de 15 anos nem participam do exame por estarem fora da escola, ou não terem alcançado a primeira das séries avaliadas no PISA ( $7^{\circ}$ ano). Cf. Folha de São Paulo, C3, 2/07/10 e Folha de São Paulo, C6, 8/12/10.

9 Durham afirma: "as faculdades de pedagogia formam professores incapazes de fazer o básico, entrar na sala de aula e ensinar a matéria. Mais grave ainda, muitos desses profissionais revelam limitações elementares: não conseguem escrever sem cometer erros de ortografia simples nem expor conceitos científicos de média complexidade. Chegam aos cursos de pedagogia com deficiências pedestres e saem de lá sem ter se livrado delas". Páginas Amarelas, Revista Veja, 26/11/08.

${ }_{10}$ Ver matéria na Folha de São Paulo, de 19/12/10, que faz uma avaliação sobre o Governo Lula trazendo números que mostram queda nos índices de pobreza, expansão do ensino superior (principalmente em razão do PROUNI), mas, por outro lado, mostra os índices insatisfatórios com relação à população adulta com ensino médio completo (39\%, abaixo da média de $44 \%$ dos países da OCDE); à população adulta com ensino superior completo (11\%, muito abaixo da média de $28 \%$

Cad. de Pesq. Interdisc. em Ci-s. Hum-s., Florianópolis, v.14, n.104, p.151-177, jan/jun 2013
} 
Dentro do quadro das novas demandas, destaca-se 0 apelo pela internacionalização, pela ampliação das relações de universidades brasileiras com universidades internacionais. ${ }^{11}$ Fala-se em reconhecimento de atividades acadêmicas desenvolvidas por alunos de graduação em instituições estrangeiras, em diplomas duplos de graduação (um nacional e outro internacional), em mobilidade do corpo docente e discente, em atrair jovens pesquisadores dos principais centros do mundo, ou seja, a ideia em pauta é a de que "na Ciência de hoje, a pesquisa atravessa os limites nacionais e rompe fronteiras entre as áreas do saber". ${ }^{12}$ Mas, como atender à pressão por internacionalização contando com os graves problemas nacionais aqui apresentados?

Outro ponto importante: a universidade democrática e de massas tornou-se, nos países periféricos, também um espaço de assistência e proteção. Passam a ser pressionadas por demandas provenientes das distintas classes sociais, especialmente das camadas mais exploradas da população, que reivindicam melhores patamares de formação e qualificação profissional como garantia de inserção no mercado. Numa tentativa de assistencialismo, o poder público tem respondido com expansão desenfreada de cursos e vagas. Um dos problemas derivados desse processo é que a assistência converteu-se num fim em si mesmo, passando a ser reivindicada por todos e convertida em direito de todos, não somente dos que efetivamente dela necessitam. "Chegou-se assim, à versão atual, que enfatiza a concessão em cascata de benefícios e subsídios, aumentando o privilégio dos privilegiados". O impacto dessas novas demandas desorganiza as bases tradicionais de trabalho da universidade e abala o que está instituído (NOGUEIRA, 2007b).

Assim, a universidade pública se vê pressionada pelo social, que no caso do Brasil, tem tido como resposta medidas assistencialistas, pressionada pela hegemônica ideia de conhecimento-mercadoria e, ainda, pelas discussões derivadas da reconfiguração do Estado enquanto provedor de bem-estar. Também tem sido pressionada pela empresa privada, tanto naquilo que se refere à gestão, como na

dos países da OCDE); ao desempenho em testes internacionais de educação (o Brasil segue entre os piores no PISA).

11 João Grandino Rodas, Reitor da Universidade de São Paulo, em entrevista ao Programa Roda Viva da TV Cultura, de 5/07/10 afirma que a sobrevivência da Universidade depende de sua internacionalização, de ser uma Universidade do mundo, com certificações internacionais.

${ }_{12}$ Palavras de Maria José S. M. Giannini, Pró-reitora de Pesquisa da UNESP. Cf. Jornal da Unesp, Universidade sem fronteiras, out. 2010.

Cad. de Pesq. Interdisc. em Ci-s. Hum-s., Florianópolis, v.14, n.104, p.151-177, jan/jun 2013 
questão de ajudá-la a selecionar seu pessoal de alto escalão. E mais, a universidade está envolvida não só na competição mercantil, mas, também, nas lutas contra a discriminação de classe, de gênero e de raça, como mostra o intenso debate sobre cotas e ações afirmativas.

Em suma, são vários os dilemas que envolvem o Estado, a sociedade e a comunidade universitária: 1) dilema entre a ideia de massificação da universidade em contraste com a preservação do nível de pesquisa e ensino; 2) entre modelos de gestão: acompanhar a exigência por resultados e eficiência e, ao mesmo tempo, assegurar a especificidade da "cultura" universitária; 3) dilema entre cientistas que dependem dos recursos do Estado, mas que brigam por autonomia universitária; 4) dilema da universidade enquanto produtora de uma ideia de cultura nacional, mas tendo de lidar com os efeitos da globalização no plano da cultura; 5) dilema entre formas de ensino presencial e virtual; e 6) dilemas sobre as novas formas de produção e aplicação do conhecimento.

Como vimos, vários autores têm refletido sobre a possibilidade de maior articulação das universidades com os governos e as indústrias, considerando a necessidade de novas formas de produzir e aplicar o conhecimento, visando às novas demandas por desenvolvimento. Ainda outros têm defendido uma ligação maior da universidade pública com o mercado, na esteira do que acontece em certas universidades norte-americanas, nas quais boa parte das linhas de financiamento de suas pesquisas depende da capacidade em captar recursos da iniciativa privada. Sem desprezar os caminhos possíveis de produção de conhecimento (e de sua aplicação) apontados por essas perspectivas, uma pergunta se faz necessária: a maior proximidade com o mercado e a entrada de dinheiro privado nas universidades não colocaria em risco a liberdade de cátedra e a liberdade das pesquisas, ou seja, não ameaçaria a autonomia da universidade, tão duramente conquistada? Dito de outro modo, quem financiaria pesquisas que resultassem em prejuízos para o mercado ou que produzissem ideias que pudessem colocar em risco o modelo de sociedade (e de capitalismo) vigente ${ }^{13}$

O papel da Universidade Pública é singular, na medida em que ela tem potencial para projetar o país, para desenhar seu futuro assumindo como

\footnotetext{
${ }^{13}$ Sobre essa questão, ver artigo Universidade, Mecenato e Mercado de Ricardo Antunes e Marcus Correia, Folha de São Paulo, 2/07/10, A3, e artigo O fortalecimento da universidade de Vladimir Safatle, Folha de São Paulo, 9/08/10, A10.
}

Cad. de Pesq. Interdisc. em Ci-s. Hum-s., Florianópolis, v.14, n.104, p.151-177, jan/jun 2013 
compromisso primeiro e inegociável a defesa da vida e do bem-estar de todos os seus cidadãos. Deve assumir o compromisso de formar quadros qualificados e competentes para pensar desafios e respostas diante da complexidade e urgência das demandas nas mais diversas áreas, mas com um diferencial: a partir de uma formação ética e cidadã. Profissionais que sejam movidos pelo saber técnico e especializado, mas que sejam casados com a ética e que priorizem as conquistas democráticas, no que diz respeito à vivência plena dos direitos e à trajetória de construção da nossa cidadania. Atores que assumam o palco do desenvolvimento tecnológico, científico e econômico, mas que, acima de qualquer coisa, sejam competentes e valentes para jogar o jogo das disputas de força e interesses movendo as peças em direção à construção de um modelo de sociedade menos excludente, mais democrático e mais justo, que tenha como objetivo maior a conquista da emancipação humana. 


\section{REFERÊNCIAS}

ARBIX, G.; CONSONI, F. Inovar para transformar a universidade brasileira. Revista Brasileira de Ciências Sociais. v. 26, n. 77, out. 2011.

BALBACHEVSKY, E. A pós-graduação no Brasil: novos desafios para uma política bem-sucedida. In: BROCK, C; SCHWARTZMAN, S. (Orgs.). Os desafios da educação no Brasil. Rio de Janeiro: Nova Fronteira, 2005.

BAUMAN, Z. O mal-estar da pós-modernidade. Rio de Janeiro: Jorge Zahar Ed., 1998.

BAUMAN, Z. Modernidade Líquida. Rio de Janeiro: Jorge Zahar Ed., 2001.

BECK, U. Modernização reflexiva: política, tradição e estética na ordem social moderna. São Paulo: Ed. UNESP, 1997.

BECK, U. Liberdade ou capitalismo. São Paulo: Ed. UNESP, 2003.

CALLON, M.; LATOUR, B. La science telle que'elle se fait. Paris: La Découverte, 1990.

CASTELLS, M. A era da informação: economia, sociedade e cultura, v. 1, São Paulo: Paz e Terra, 1999 a.

CASTRO, M. H. de M. Estado e mercado na regulação da educação superior. Os desafios da educação no Brasil. Rio de Janeiro: Nova Fronteira, 2005.

CUNHA, L. A. O desenvolvimento meandroso da educação brasileira entre o Estado e o Mercado. Educação e Sociedade, Campinas, v. 28, n. 100, Especial, p. 809-829, out. 2007.

DRAIBE, S. Uma nova institucionalidade das políticas públicas sociais? Reflexões a propósito da experiência latino-americana recente de reformas e programas sociais. In: São Paulo em Perspectiva, v. 11, n. 4, out/dez. 1997.

DURHAM, E. R. Educação superior, pública e privada (1808-2000). In: BROCK, C; SCHWARTZMAN, S. (Orgs.). Os desafios da educação no Brasil. Rio de Janeiro: Nova Fronteira, 2005. 
DURHAM, E. R. O ensino superior em São Paulo. Diagnóstico. Seminários do Núcleo de Pesquisa de Políticas Públicas, 2009.

FUNTOWICZ, S; RAVETZ, J. Epistemologia Politica: Ciencia con la gente. Centro Edit. Am. Latina, Buenos Aires, 1993.

GIBBONS, M. et al. The new production of knowledge: the dynamics of science in contemporary societies. London: Sage, 1994.

GIDDENS, A. As consequências da modernidade. São Paulo: Ed. UNESP, 1991.

GIDDENS, A. Mundo em descontrole. Rio de Janeiro: Record, 2002.

HARVEY, D. Condição pós-moderna. São Paulo: Loyola, 2003.

IANNI, O. Teorias da globalização. Rio de Janeiro: Civilização Brasileira, 1999.

LASTRES, H. M. M. et al. Desafios e oportunidades da Era do Conhecimento. São Paulo em Perspectiva, v.3, n.16, p. 60-66. 2002.

LEYDESDORFF, L.; ETZKOWITZ, $\mathrm{H}$. The Triple Helix as a model for innovation studies. Science and Public Policy, v. 3, n. 25, p. 195-203. 1998

LIMA, L. C.; AZEVEDO, M. L. N.; CATANI, A. M. O processo de Bolonha, a Avaliação da Educação Superior e algumas considerações sobre a Universidade Nova. Avaliação, Campinas; Sorocaba, SP, v.13, n.1, p.7-36, mar. 2008.

LIMA, P. G.; CASTRO, F.; CARVALHO, M. A. V. Caminhos da universidade rumo ao século XXI: pontos e estratégias para a sua orientação na visão de educadores brasileiros. Paidéia, FFCLRP-USP, Ribeirão Preto, jan/jul. 2000.

LIPOVETSKY, G. Os Tempos Hipermodernos. São Paulo: Editora Barcarolla, 2004. MARCOVITCH, J. A informação e o conhecimento. São Paulo em Perspectiva, v. 4, n.16, p. 3-8. 2002.

MARTINS, C. B. A reforma universitária de 1968 e a abertura para o ensino superior privado no Brasil. Educação \& Sociedade, Campinas, v. 30, n. 106, p. 15-35, jan/abr. 2009. 
MELLO, J. M. C. A abordagem da Hélice Tríplice e o Desenvolvimento Regional. II Seminário Internacional Empreendedorismo, Pequenas e Médias Empresas e desenvolvimento local. Rio de Janeiro, 02 a 04 de agosto de 2004.

MORGADO, J. C. Processo de Bolonha e Ensino Superior num mundo globalizado. Educação \& Sociedade, Campinas, v. 30, n. 106, p. 37-62, jan./abr. 2009.

NOGUEIRA, M. A. Sofrimento organizacional, democracia e gestão universitária. In: TÓVOLI, E. M. G.; SEGATTO, J. A.; NOGUEIRA, M. A. Gestão universitária. Araraquara: Laboratório Editorial/FCL, UNESP, 2005.

NOGUEIRA, M. A. Hipermodernidade Periférica, Política e Democracia. Anais da ANPOCS, 2006.

NOGUEIRA, M. A. Bem mais que pós-moderno: poder, sociedade civil e democracia na modernidade periférica radicalizada. Ciências Sociais Unisinos, v. 43, n. 1, jan./abr. 2007a.

NOGUEIRA, M. A. Tempo de autocrítica. O Estado de São Paulo. 06 jun, p. A2, 2007 b.

SINGER, P. A universidade no olho do furacão. In: Estudos Avançados, Dossiê Educação, v. 15, n. 42, maio/ago. 2001.

SOUZA, A.; LAMOUNIER, B. A Classe Média Brasileira, Rio de Janeiro: Elsevier; Brasília: CNI, 2010.

SOARES, L. E. A política nacional de segurança pública: histórico, dilemas e perspectivas. In: Estudos Avançados, n.61, v. 21, set./dez. 2007.

WANDERLEY, L. E. W. O que é Universidade. São Paulo: Brasiliense, 2003.

Artigo:

Recebido em: 24/01/2013

Aceito em: 15/07/2013 